\title{
Thermal Stability and Crystallization of Iron and Cobalt - Based Bulk Amorphous Alloys
}

\author{
J. Olszewski ${ }^{a}$, J. ZBroszczyK ${ }^{a}$, K. SobczyK ${ }^{a}$, \\ W. Ciurzyńska ${ }^{a}$, P. Brągiel ${ }^{b}$, M. NAbialeK $^{a}$, \\ J. ŚWIERCZEK ${ }^{a}$, M. HASIAK ${ }^{c}$ AND A. EUKIEWSKA ${ }^{a}$ \\ ${ }^{a}$ Institute of Physics, Czȩstochowa University of Technology \\ al. Armii Krajowej 19, 42-200 Czȩstochowa, Poland \\ ${ }^{b}$ Institute of Physics, Jan Długosz University \\ al. Armii Krajowej 15, 42-200 Czȩstochowa, Poland \\ ${ }^{c}$ Institute of Materials Science and Applied Mechanics \\ Wrocław University of Technology \\ Smoluchowskiego 25, 50-370 Wrocław, Poland
}

\begin{abstract}
Microstructure by the Mössbauer spectroscopy and approach to magnetic saturation in the bulk amorphous $\mathrm{Fe}_{61} \mathrm{Co}_{10} \mathrm{Me}_{7} \mathrm{Y}_{2} \mathrm{~B}_{20}\left(\mathrm{Me}_{7}=\mathrm{Y}_{7}\right.$, $\mathrm{Y}_{6} \mathrm{Ti}_{1}$ or $\mathrm{Zr}_{2.5} \mathrm{Hf}_{2.5} \mathrm{~W}_{2}$ ) alloys are investigated. The bulk amorphous $\mathrm{Fe}_{61} \mathrm{Co}_{10} \mathrm{Zr}_{2.5} \mathrm{Hf}_{2.5} \mathrm{~W}_{2} \mathrm{Y}_{2} \mathrm{~B}_{20}$ alloy exhibits the best thermal stability and remains amorphous up to $901 \mathrm{~K}$. Moreover, the quasi-dislocations dipoles present in this amorphous alloy have the largest width equal to $6.7 \mathrm{~nm}$. After annealing this alloy below the crystallization temperature the enhancement of both the average hyperfine field and its standard deviation is observed which points to the increase in the atom packing density due to the decay of quasi-dislocation dipoles. After the annealing at $901 \mathrm{~K}$ the small amount of the crystalline $\alpha$-FeCo phase is presented in this alloy. The same crystalline phase appears in the bulk $\mathrm{Fe}_{61} \mathrm{Co}_{10} \mathrm{Y}_{8} \mathrm{Ti}_{1} \mathrm{~B}_{20}$ and $\mathrm{Fe}_{61} \mathrm{Co}_{10} \mathrm{Y}_{9} \mathrm{~B}_{20}$ alloys after annealing at $750 \mathrm{~K}$ and $840 \mathrm{~K}$, respectively.
\end{abstract}

PACS numbers: $75.50 . \mathrm{Kj}, 75.50 . \mathrm{Bb}, 76.80 .+\mathrm{y}$

\section{Introduction}

Most iron based amorphous alloys exhibit excellent soft magnetic properties and are interesting materials from both scientific and practical point of view. In 
order to obtain bulk amorphous alloys the three following rules should be fulfilled [1]:

1. the material has to contain more than three elements,

2. the main elements should exhibit negative heat of mixing,

3 . the difference in the atomic radii of main components should be larger than $12 \%$.

In these alloys the short range interactions are more energetically favorable than long range ones characteristic of crystalline materials. Moreover, the multicomponent systems show large viscosity in the molten state that hinders the atomic motions and limits creation of crystal nuclei during the sample preparation. The materials obeying the mentioned above rules show a wide super-cooled liquid region which leads to a high glass forming ability giving an opportunity to produce bulk amorphous alloys in the form of thick ribbons (about $100 \mu \mathrm{m}$ in thickness), rods, tubes and plates at lower quenching rates than in the case of classical amorphous alloys [2]. The low quenching rate enables the structure relaxations during the sample preparations which lead to the increase in the atom packing density and the change of the average hyperfine field in the case of ferromagnets. Therefore, the Mössbauer spectroscopy is a good tool for the microstructure studies of these materials. However, the approach to ferromagnetic saturation studies give the direct information about the structure defects in the investigated alloys.

In this paper we present the results of thermal stability, early stages of crystallization and high magnetic field properties studies of the bulk $\mathrm{Fe}_{61} \mathrm{Co}_{10} \mathrm{Me}_{7} \mathrm{Y}_{2} \mathrm{~B}_{20}\left(\mathrm{Me}_{7}=\mathrm{Y}_{7}, \mathrm{Y}_{6} \mathrm{Ti}_{1}\right.$ or $\left.\mathrm{Zr}_{2.5} \mathrm{Hf}_{2.5} \mathrm{~W}_{2}\right)$ amorphous alloys.

\section{Experimental procedure}

Ingots of the proper alloys were prepared by arc melting in a protective argon atmosphere. In order to obtain homogeneous materials the ingots were remelted three times. The bulk amorphous samples of the $\mathrm{Fe}_{61} \mathrm{Co}_{10} \mathrm{Me}_{7} \mathrm{Y}_{2} \mathrm{~B}_{20}$ $\left(\mathrm{Me}_{7}=\mathrm{Y}_{7}, \mathrm{Y}_{6} \mathrm{Ti}_{1}\right.$ or $\left.\mathrm{Zr}_{2.5} \mathrm{Hf}_{2.5} \mathrm{~W}_{2}\right)$ alloys in the form of plates $0.5 \mathrm{~mm}$ thick were produced by a suction casting method [3]. The microstructure of the samples was studied by X-ray diffraction and the Mössbauer spectroscopy. The transmission Mössbauer spectra for the powdered samples were measured at room temperature using conventional Mössbauer spectrometer working at a constant acceleration with a ${ }^{57} \mathrm{Co}(\mathrm{Rh})$ radioactive source of the $70 \mathrm{mCi}$ in activity. The spectra were fitted by Normos package [4]. From the Mössbauer spectra of the amorphous samples the hyperfine field distributions were obtained using the Hesse-Rübartsch method [5] assuming the linear dependence of the isomer shift (IS) on the hyperfine field $\left(B_{\mathrm{hf}}\right)$ :

$$
\mathrm{IS}=\mathrm{IS}_{0}+b B_{\mathrm{hf}} .
$$

The Mössbauer spectra of the partially crystallized alloys were analyzed as superposition of the spectra corresponding to the amorphous matrix and crystalline 
phase [6]. The spectrum corresponding to the amorphous matrix was analyzed in the same way as the Mössbauer spectra of the amorphous alloys. However, the Mössbauer spectrum corresponding to the crystalline phase was analyzed under assumption of the Gaussian distribution of the hyperfine field whose average value depends on Co concentration in this phase [7]. The Mössbauer studies were carried out for the as-quenched samples and after the accumulative annealing below the crystallization temperature, i.e. at $750 \mathrm{~K}$ for $1 \mathrm{~h}, 840 \mathrm{~K}$ for $0.5 \mathrm{~h}$ and $870 \mathrm{~K}$ for $0.5 \mathrm{~h}$ and at $901 \mathrm{~K}$ for $0.5 \mathrm{~h}$.

In order to determine the proper annealing temperature the differential scanning calorimetry (DSC) curves at the heating rate of $10 \mathrm{~K} / \mathrm{min}$ were recorded. The Curie temperature of the investigated alloys were derived from the thermomagnetic curves obtained by a force magnetometer. High field magnetization curves were measured by a vibrating sample magnetometer (VSM) in magnetic field up to $2 \mathrm{~T}$ for the sample $5 \mathrm{~mm}$ long and $1 \mathrm{~mm}$ wide cut out from the plates. The magnetizing field was parallel to the sample length to minimize demagnetization effect. The magnetization curves were analyzed using the least squares method and the quasi-dislocation dipoles width was determined.

\section{Results and discussion}

The X-ray diffraction patterns for the investigated alloys in the as-quenched state exhibit single broad maxima typical of amorphous materials. Transmission Mössbauer spectra for the as-quenched $\mathrm{Fe}_{61} \mathrm{Co}_{10} \mathrm{Me}_{7} \mathrm{Y}_{2} \mathrm{~B}_{20}\left(\mathrm{Me}_{7}=\mathrm{Y}_{7}, \mathrm{Y}_{6} \mathrm{Ti}_{1}\right.$ or $\mathrm{Zr}_{2.5} \mathrm{Hf}_{2.5} \mathrm{~W}_{2}$ ) alloys and corresponding hyperfine magnetic field distributions $P\left(B_{\mathrm{hf}}\right)$ are presented in Fig. 1 . The spectra are asymmetric and consist of broad overlapping lines characteristic of amorphous ferromagnets. The wide $P\left(B_{\mathrm{hf}}\right)$ curves indicate the great number of non-equivalent Fe sites with different topological and chemical short range order of atoms. From Fig. 1 one can see that at least two components in hyperfine field distributions corresponding to the regions with different iron concentration can be distinguished. The average hyperfine field induction, $\left(B_{\text {eff }}\right)_{\text {am }}$, its standard deviation $D_{\text {am }}$, parameters of the linear dependence IS $=F\left(B_{\mathrm{hf}}\right)($ Eq. (1)) for the amorphous alloys and matrix of partially crystallized samples are listed in Table. The hyperfine parameters of the crystalline phase are also collected in Table. The highest average hyperfine field equal to $20.83 \mathrm{~T}$ in the as-quenched state is exhibited by the $\mathrm{Fe}_{61} \mathrm{Co}_{10} \mathrm{Y}_{8} \mathrm{Ti}_{1} \mathrm{~B}_{20}$ alloy. Simultaneously, the hyperfine field distribution of this alloy shows the largest standard deviation (Table) which indicates the presence of the largest number of non-equivalent $\mathrm{Fe}$ sites.

The DSC curves obtained for investigated alloys exhibit one exothermal peak. The temperatures of the onset crystallization determined from these curves are equal to $901 \mathrm{~K}, 935 \mathrm{~K}$ and $950 \mathrm{~K}$ for the bulk amorphous $\mathrm{Fe}_{61} \mathrm{Co}_{10} \mathrm{Zr}_{2.5} \mathrm{Hf}_{2.5} \mathrm{~W}_{2} \mathrm{Y}_{2} \mathrm{~B}_{20}, \mathrm{Fe}_{61} \mathrm{Co}_{10} \mathrm{Y}_{8} \mathrm{Ti}_{1} \mathrm{~B}_{20}$ and $\mathrm{Fe}_{61} \mathrm{Co}_{10} \mathrm{Y}_{9} \mathrm{~B}_{20}$ alloys, respectively. After annealing at $750 \mathrm{~K}$ (well below the crystallization temperature) 


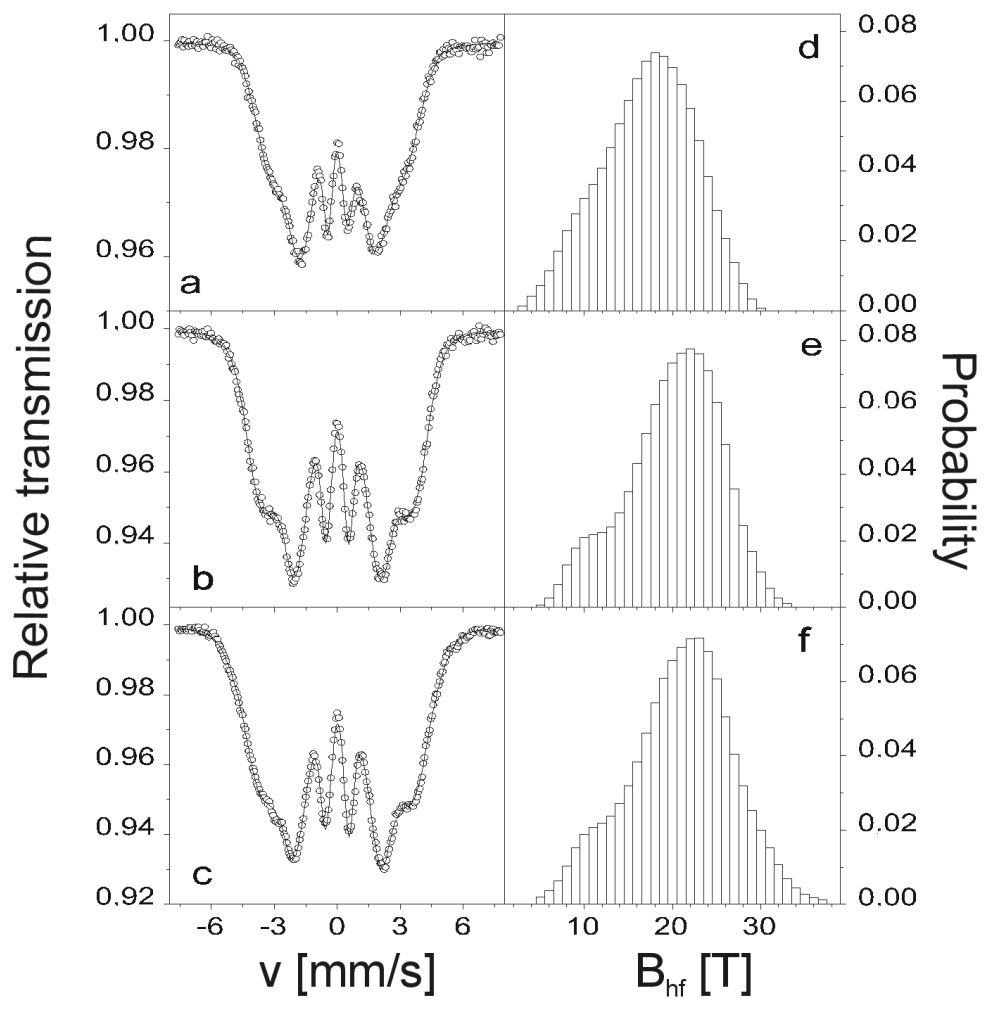

Fig. 1. Transmission Mössbauer spectra and corresponding hyperfine field distributions of the bulk amorphous $\mathrm{Fe}_{61} \mathrm{Co}_{10} \mathrm{Zr}_{2.5} \mathrm{Hf}_{2.5} \mathrm{~W}_{2} \mathrm{Y}_{2} \mathrm{~B}_{20}$ (a, d), $\mathrm{Fe}_{61} \mathrm{Co}_{10} \mathrm{Y}_{9} \mathrm{~B}_{20}$ (b, e) and $\mathrm{Fe}_{61} \mathrm{Co}_{10} \mathrm{Y}_{8} \mathrm{Ti}_{1} \mathrm{~B}_{20}(\mathrm{c}, \mathrm{f})$ alloys in the as-quenched state.

for $1 \mathrm{~h}$ the average hyperfine field in the case of the $\mathrm{Fe}_{61} \mathrm{Co}_{10} \mathrm{Zr}_{2.5} \mathrm{Hf}_{2.5} \mathrm{~W}_{2} \mathrm{Y}_{2} \mathrm{~B}_{20}$ alloy increases from $17.17 \mathrm{~T}$ up to $17.36 \mathrm{~T}$. However, in the case of the $\mathrm{Fe}_{61} \mathrm{Co}_{10} \mathrm{Y}_{9} \mathrm{~B}_{20}$ alloy no significant changes of $\left(B_{\text {eff }}\right)_{\text {am }}$ are observed proving the best thermal stability of this alloy during annealing at relatively low temperature $(750 \mathrm{~K})$. As for the $\mathrm{Fe}_{61} \mathrm{Co}_{10} \mathrm{Y}_{8} \mathrm{Ti}_{1} \mathrm{~B}_{20}$ alloy after this annealing in the Mössbauer spectrum the sextet appears which is ascribed to the crystalline phase (Fig. 2a, d). The appearance of the crystalline grains seems to be connected with growing up of the nuclei frozen in the samples during preparation [8]. Taking into account the hyperfine field parameters of the crystalline phase listed in Table the crystalline grains can be ascribed to the $\alpha$-FeCo phase with about 20 at. $\%$ of Co. After the subsequent annealing of the samples at $840 \mathrm{~K}$ for $0.5 \mathrm{~h}$ the small volume fraction of the crystalline $\alpha$-FeCo phase equal to 0.02 in $\mathrm{Fe}_{61} \mathrm{Co}_{10} \mathrm{Y}_{9} \mathrm{~B}_{20}$ alloy (Fig. 2b, e) is found. After the additional heat treatment at $870 \mathrm{~K}$ for $0.5 \mathrm{~h}$ the volume fraction of this phase increases up to 0.05 (Table). However, no change in the amount of the crystalline phase in the case of the $\mathrm{Fe}_{61} \mathrm{Co}_{10} \mathrm{Y}_{8} \mathrm{Ti}_{1} \mathrm{~B}_{20}$ alloy with the increase in the annealing temperature is observed (Table). As far as the 
TABLE

The average hyperfine field induction $\left(B_{\text {eff }}\right)_{\text {am }}$, its standard deviation $D_{\text {am }}$, parameters $\left(\mathrm{IS}_{0}\right)$ and $(b)$ of the linear dependence IS $=F\left(B_{\mathrm{hf}}\right)$ (Eq. (1)) for the amorphous alloys and matrix of partially crystallized samples, hyperfine field induction $\left(B_{\mathrm{cr}}\right)$, isomer shift $\left(\mathrm{IS}_{\mathrm{cr}}\right)$ and volume fraction $(V)$ of the crystalline phase for investigated alloys after different heat treatments. Uncertainties for the last significant figure are given in brackets.

\begin{tabular}{|c|c|c|c|c|c|c|c|}
\hline $\begin{array}{c}\text { Thermal } \\
\text { history of the } \\
\text { sample }\end{array}$ & $\begin{array}{c}\left(B_{\text {eff }}\right)_{\mathrm{am}} \\
{[\mathrm{T}]}\end{array}$ & $D_{\mathrm{am}}[\mathrm{T}]$ & $\begin{array}{c}\mathrm{IS}_{0} \times 10^{2} \\
{\left[\frac{\mathrm{mm}}{\mathrm{s}}\right]}\end{array}$ & $\begin{array}{c}b \times 10^{4} \\
{\left[\frac{\mathrm{mm}}{\mathrm{sT}}\right]}\end{array}$ & $B_{\mathrm{cr}}[\mathrm{T}]$ & $\begin{array}{c}\mathrm{IS}_{\mathrm{cr}} \times 10^{2} \\
{\left[\frac{\mathrm{mm}}{\mathrm{s}}\right]}\end{array}$ & $\bar{V}$ \\
\hline \multicolumn{8}{|c|}{$\mathrm{Fe}_{61} \mathrm{Co}_{10} \mathrm{Zr}_{2.5} \mathrm{Hf}_{2.5} \mathrm{~W}_{2} \mathrm{Y}_{2} \mathrm{~B}_{20}$} \\
\hline as-quenched & $17.17(4)$ & $5.26(4)$ & $-6(1)$ & $44(6)$ & - & - & - \\
\hline $750 \mathrm{~K} \backslash 1 \mathrm{~h}$ & $17.36(3)$ & $5.32(3)$ & $-5.0(7)$ & $37(4)$ & - & - & - \\
\hline $840 \mathrm{~K} \backslash 0.5 \mathrm{~h}$ & $17.86(4)$ & $5.87(5)$ & $-3.2(9)$ & $30(5)$ & - & - & - \\
\hline $870 \mathrm{~K} \backslash 0.5 \mathrm{~h}$ & $20.29(4)$ & $6.42(4)$ & $4.9(8)$ & $-24(4)$ & - & - & - \\
\hline $901 \mathrm{~K} \backslash 0.5 \mathrm{~h}$ & $17.38(6)$ & $7.57(6)$ & $9(1)$ & $-37(5)$ & $34.7(3)$ & $4(1)$ & 0.05 \\
\hline \multicolumn{8}{|c|}{$\mathrm{Fe}_{61} \mathrm{Co}_{10} \mathrm{Y}_{9} \mathrm{~B}_{20}$} \\
\hline as-quenched & $20.05(4)$ & $5.32(4)$ & $1.5(8)$ & $-7(5)$ & - & - & - \\
\hline $750 \mathrm{~K} \backslash 1 \mathrm{~h}$ & $20.04(4)$ & $5.48(4)$ & $2.8(7)$ & $-15(6)$ & - & - & - \\
\hline $840 \mathrm{~K} \backslash 0.5 \mathrm{~h}$ & $20.04(4)$ & $5.39(4)$ & $4.1(8)$ & $-20(6)$ & $34.9(2)$ & $5(1)$ & 0.02 \\
\hline $870 \mathrm{~K} \backslash 0.5 \mathrm{~h}$ & $20.19(4)$ & $5.45(4)$ & $5.4(8)$ & $-28(4)$ & $35.1(2)$ & $5(1)$ & 0.05 \\
\hline \multicolumn{8}{|c|}{$\mathrm{Fe}_{61} \mathrm{Co}_{10} \mathrm{Y}_{8} \mathrm{Ti}_{1} \mathrm{~B}_{20}$} \\
\hline as-quenched & $20.83(4)$ & $5.85(4)$ & $5.3(5)$ & $-28(3)$ & - & - & - \\
\hline $750 \mathrm{~K} \backslash 1 \mathrm{~h}$ & $20.72(4)$ & $5.65(3)$ & $6.6(5)$ & $-36(3)$ & $34.4(4)$ & $5(1)$ & 0.02 \\
\hline $840 \mathrm{~K} \backslash 0.5 \mathrm{~h}$ & $20.82(3)$ & $5.66(3)$ & $4.9(4)$ & $-27(2)$ & $34.6(3)$ & $5(1)$ & 0.02 \\
\hline $870 \mathrm{~K} \backslash 0.5 \mathrm{~h}$ & $20.90(3)$ & $5.66(3)$ & $4.9(5)$ & $-27(3)$ & $34.6(3)$ & $5(1)$ & 0.02 \\
\hline
\end{tabular}

$\mathrm{Fe}_{61} \mathrm{Co}_{10} \mathrm{Zr}_{2.5} \mathrm{Hf}_{2.5} \mathrm{~W}_{2} \mathrm{Y}_{2} \mathrm{~B}_{20}$ alloy is concerned, it remains fully amorphous after the annealing at $840 \mathrm{~K}$ and then at $870 \mathrm{~K}$ for $0.5 \mathrm{~h}$. However, after these treatments the enhancement of the average hyperfine field takes place which indicates that the atom packing density increases. One may conclude that this alloy is resistant to crystallization and crystalline phase appears only after the annealing at the temperature near the onset of crystallization (901 K) (Fig. 2c, f). The appearance of the crystalline phase in thess alloys is accompanied by distinct changes in the microstructure of the amorphous matrix (Fig. 2f). In the hyperfine field distribution of the amorphous matrix at least four components corresponding to different iron environments are present indicating its heterogeneity.

Similarly to the classical, in the bulk amorphous alloys structure defects as point-like defects and linear ones that are created by conglomeration of point-like defects, called quasi-dislocation dipoles occur and due to magnetoelastic coupling influence the magnetization behavior in the vicinity of the ferromagnetic satu- 


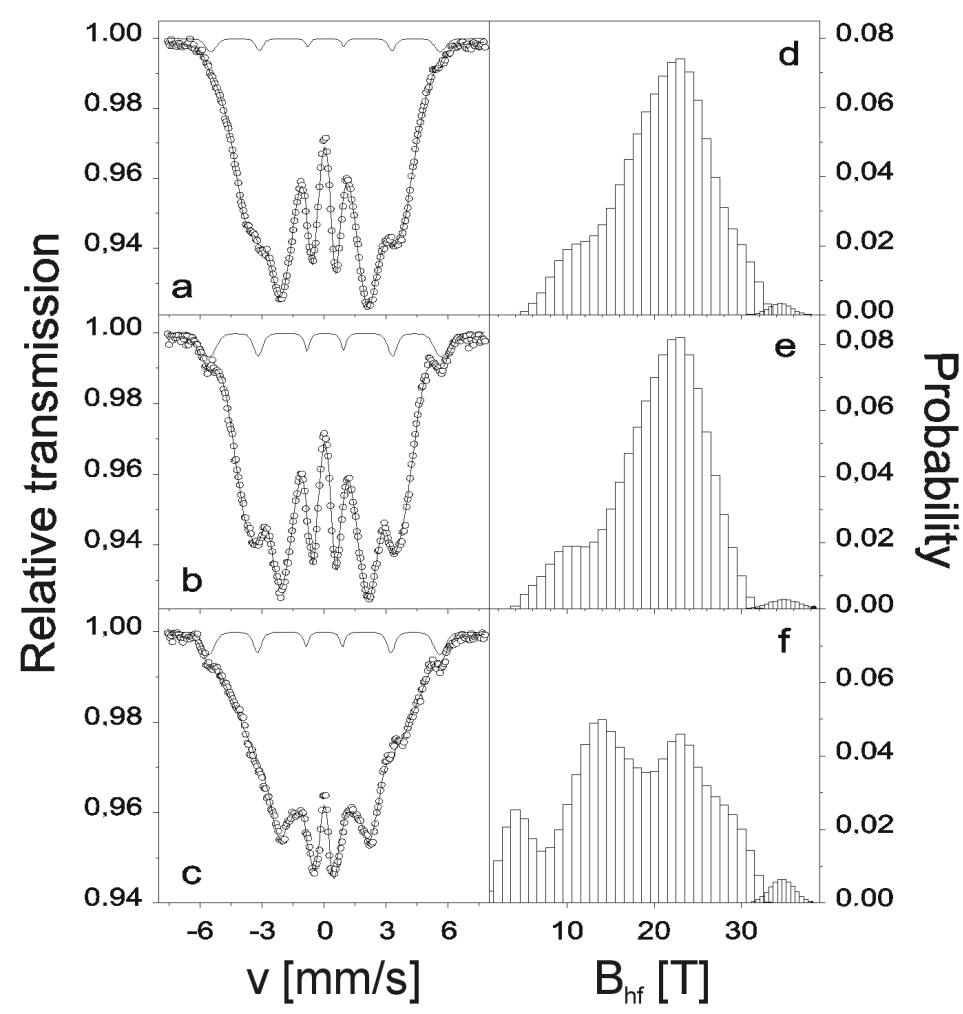

Fig. 2. Transmission Mössbauer spectra and corresponding hyperfine field distributions of the annealed alloys: $\mathrm{Fe}_{61} \mathrm{Co}_{10} \mathrm{Y}_{8} \mathrm{Ti}_{1} \mathrm{~B}_{20}$ at $750 \mathrm{~K}$ for $1 \mathrm{~h}(\mathrm{a}, \mathrm{d})$, the $\mathrm{Fe}_{61} \mathrm{Co}_{10} \mathrm{Y}_{9} \mathrm{~B}_{20}$ at $750 \mathrm{~K}$ for $1 \mathrm{~h}$ and $840 \mathrm{~K}$ for $0.5 \mathrm{~h}$ (b, e), the $\mathrm{Fe}_{61} \mathrm{Co}_{10} \mathrm{Zr}_{2.5} \mathrm{Hf}_{2.5} \mathrm{~W}_{2} \mathrm{Y}_{2} \mathrm{~B}_{20}$ at $750 \mathrm{~K}$ for $1 \mathrm{~h}, 840 \mathrm{~K}$ for $0.5 \mathrm{~h}, 870 \mathrm{~K}$ for $0.5 \mathrm{~h}$ and $901 \mathrm{~K}$ for $0.5 \mathrm{~h}$ (c,f).

ration. It is known that at a high magnetic field, when the magnetic domain structure is not present in the sample, the magnetic polarization can be described by the relation $[9]$ :

$$
\mu_{0} M(H)=\mu_{0} M_{\mathrm{S}}\left(1-\sum_{i} \frac{a_{i}}{\left(\mu_{0} H\right)^{i}}\right)+b\left(\mu_{0} H\right)^{\frac{1}{2}},
$$

where $\mu_{0} M_{\mathrm{S}}$ is the magnetic saturation polarization at a given temperature, terms $\frac{a_{i}}{\left(\mu_{0} H\right)^{i}}$ are connected with different kinds of defects: $i=1 / 2$ for point like defects, $i=1$ and 2 for quasi-dislocation dipoles, the last term is ascribed to the Holstein-Primakoff paraprocess. Exemplary magnetization curves $\frac{M}{M_{\mathrm{S}}}\left(\frac{1}{\mu_{0} H}\right)$ and $\frac{M}{M_{\mathrm{S}}}\left(\frac{1}{\left(\mu_{0} H\right)^{2}}\right)$ for the as-quenched $\mathrm{Fe}_{61} \mathrm{Co}_{10} \mathrm{Zr}_{2.5} \mathrm{Hf}_{2.5} \mathrm{~W}_{2} \mathrm{Y}_{2} \mathrm{~B}_{20}$ alloy are shown in Fig. 3. It can be seen that the linear dependences $\frac{M}{M_{\mathrm{S}}}\left(\frac{1}{\mu_{0} H}\right)$ in the field range 0.03-0.10 T (Fig. 3a) and $\frac{M}{M_{\mathrm{S}}}\left(\frac{1}{\left(\mu_{0} H\right)^{2}}\right)$ in the field range 0.13-0.22 $\mathrm{T}$ are observed 


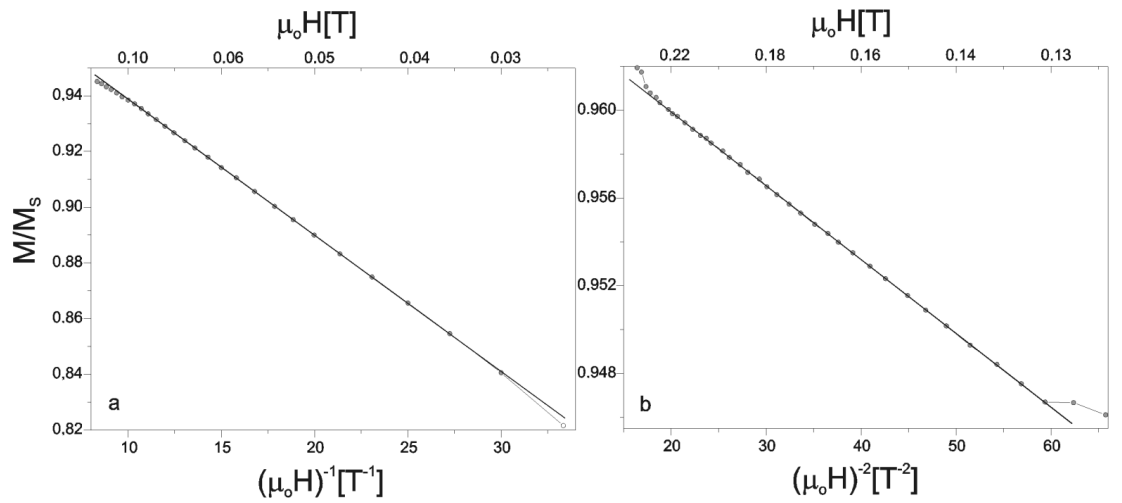

Fig. 3. Relative magnetization $M / M_{\mathrm{S}}$ versus $1 /\left(\mu_{0} H\right)$ (a) and versus $1 /\left(\mu_{0} H\right)^{2}$ (b) for the as-quenched bulk amorphous $\mathrm{Fe}_{61} \mathrm{Co}_{10} \mathrm{Zr}_{2.5} \mathrm{Hf}_{2.5} \mathrm{~W}_{2} \mathrm{Y}_{2} \mathrm{~B}_{20}$ alloy.

(Fig. 3b). According to the Kronmüller theory [9] the evaluated width of quasidislocation dipoles for this alloy is equal to $6.7 \mathrm{~nm}$. The large quasi-dislocation dipoles may decay to the smaller ones during the annealing giving rise to the increase of the atomic packing density in amorphous state which is confirmed by the Mössbauer spectroscopy studies (Table). The relative magnetization for the asreceived $\mathrm{Fe}_{61} \mathrm{Co}_{10} \mathrm{Y}_{9} \mathrm{~B}_{20}$ alloy is linearly dependent on the reciprocal of $\frac{1}{\sqrt{\mu_{0} H}}$ and $\frac{1}{\mu_{0} H}$ in the field ranges from $0.04 \mathrm{~T}$ to $0.14 \mathrm{~T}$ (Fig. 4a) and from $0.14 \mathrm{~T}$ to $0.34 \mathrm{~T}$ (Fig. 4b), respectively. The similar behavior is observed for the $\mathrm{Fe}_{61} \mathrm{Co}_{10} \mathrm{Y}_{8} \mathrm{Ti}_{1} \mathrm{~B}_{20}$

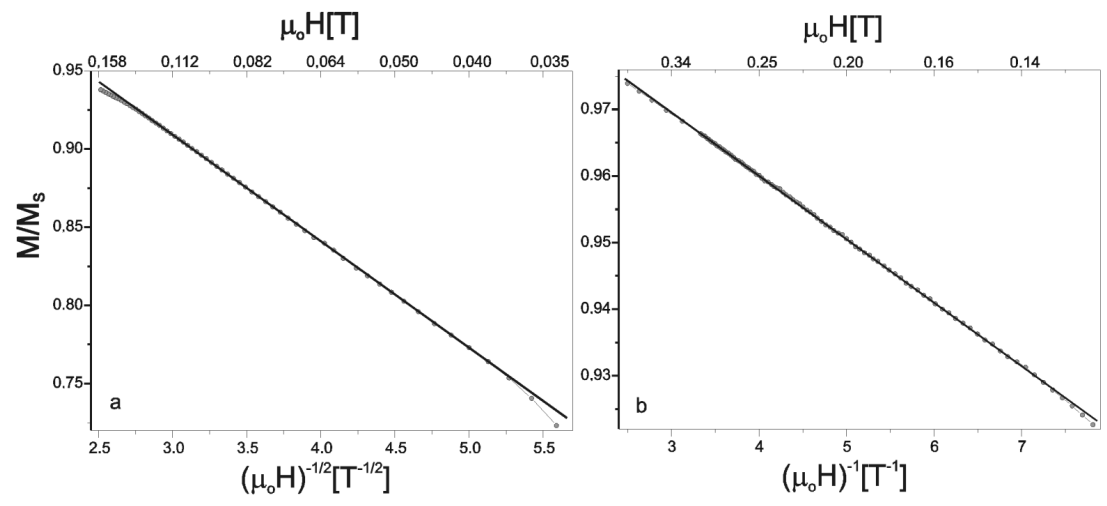

Fig. 4. Relative magnetization $M / M_{\mathrm{S}}$ versus $1 /\left(\mu_{0} H\right)^{-1 / 2}$ (a) and $1 /\left(\mu_{0} H\right)$ (b) for the as-quenched bulk amorphous $\mathrm{Fe}_{61} \mathrm{Co}_{10} \mathrm{Y}_{9} \mathrm{~B}_{20}$ alloy.

alloy. In the case of $\mathrm{Fe}_{61} \mathrm{Co}_{10} \mathrm{Y}_{8} \mathrm{Ti}_{1} \mathrm{~B}_{20}$ and $\mathrm{Fe}_{61} \mathrm{Co}_{10} \mathrm{Y}_{9} \mathrm{~B}_{20}$ alloys this relative magnetization behavior is connected with point-like defects (Fig. 4a) and quasidislocation dipoles (Fig. 4b). The estimated width of the quasi-dislocation dipoles is equal to $3.1 \mathrm{~nm}$ and $4.2 \mathrm{~nm}$ for the $\mathrm{Fe}_{61} \mathrm{Co}_{10} \mathrm{Y}_{8} \mathrm{Ti}_{1} \mathrm{~B}_{20}$ and $\mathrm{Fe}_{61} \mathrm{Co}_{10} \mathrm{Y}_{9} \mathrm{~B}_{20}$ al- 
loys, respectively. The smaller quasi-dislocation dipoles seem to be more stable than larger ones, observed in the bulk amorphous $\mathrm{Fe}_{61} \mathrm{Co}_{10} \mathrm{Zr}_{2.5} \mathrm{Hf}_{2.5} \mathrm{~W}_{2} \mathrm{Y}_{2} \mathrm{~B}_{20}$ alloy, resulting in small changes of the average hyperfine field within the amorphous state (Table).

\section{Conclusions}

The bulk $\mathrm{Fe}_{61} \mathrm{Co}_{10} \mathrm{Me}_{7} \mathrm{Y}_{2} \mathrm{~B}_{20}\left(\mathrm{Me}_{7}=\mathrm{Y}_{7}, \mathrm{Y}_{6} \mathrm{Ti}_{1}\right.$ or $\left.\mathrm{Zr}_{2.5} \mathrm{Hf}_{2.5} \mathrm{~W}_{2}\right)$ alloys obtained by a suction casting method in the form of plates are fully amorphous. However, they are not homogeneous and in the hyperfine field distributions at least two components corresponding to the regions with different iron concentration can be distinguished. The structure relaxations occurring during annealing below the crystallization temperature lead to the increase in the atom packing density which involves the enhancement of both the average hyperfine field and standard deviation of the hyperfine field distribution. This effect is the most distinct in the case of the $\mathrm{Fe}_{61} \mathrm{Co}_{10} \mathrm{Zr}_{2.5} \mathrm{Hf}_{2.5} \mathrm{~W}_{2} \mathrm{Y}_{2} \mathrm{~B}_{20}$ alloy. The latter alloy shows also the largest width of the quasi-dislocation dipoles $(6.7 \mathrm{~nm})$ and is the most resistant to the crystallization.

\section{References}

[1] A. Inoue, Acta Mater. 48, 279 (2000).

[2] A. Inoue, J.S. Gook, JIM Trans. Mat. 36, 1180 (1995).

[3] J. Zbroszczyk, J. Olszewski, W.H. Ciurzyńska, M. Nabiałek, P. Pawlik, M. Hasiak, A. Łukiewska, K. Perduta, J. Magn. Magn. Mater. 304, e724 (2006).

[4] R.A. Brand, Nucl. Instrum. Methods Phys. Res. B 28, 398 (1987).

[5] J. Hesse, A. Rübartsch, J. Phys. E, Sci. Instrum. 7, 526 (1974).

[6] W.H. Ciurzyńska, L.K. Varga, J. Olszewski, J. Zbroszczyk, M. Hasiak, J. Magn. Magn. Mater. 208, 61 (2000).

[7] J.E. Frąckowiak, Phys. Status Solidi A 87, 109 (1985).

[8] J. Olszewski, J. Zbroszczyk, H. Fukunaga, W. Ciurzyńska, A. Łukiewska, M. Piasecki, P. Bra̧giel, K. Perduta, A. Młyńczyk, J. Lelątko, J. Magn. Magn. Mater. 241, 381 (2002).

[9] H. Kronmüller, J. Phys. (France) 41, 518 (1980). 